\title{
Clinical characteristics of hereditary neuropathy with liability to pressure palsy presenting with monoparesis in the emergency department
}

\author{
Changho Kim ${ }^{1}$, Jin-Sung Park ${ }^{2}$ \\ ${ }^{1}$ Department of Emergency Medicine, Kyungpook National University Chilgok Hospital, School of Medicine, Kyungpook National University, \\ Daegu, Korea \\ ${ }^{2}$ Department of Neurology, Kyungpook National University Chilgok Hospital, School of Medicine, Kyungpook National University, Daegu, Korea
}

Received: June 9, 2020

Revised: July 17, 2020

Accepted: July 17, 2020

Corresponding author:

Jin-Sung Park

Department of Neurology,

Kyungpook National University

Chilgok Hospital, School of

Medicine, Kyungpook National

University, 807 Hoguk-ro, Buk-gu,

Daegu 41404, Korea

Tel: +82-53-200-2753

Fax: +82-53-200-2029

E-mail:neurojspark@gmail.com
Hereditary neuropathy with liability to pressure palsy (HNPP) is a rare neurological genetic disease caused by deletion of the peripheral myelin protein 22 gene and presents in childhood or young adulthood. We report four cases of HNPP with typical and rare presentations, reflecting the broad clinical spectrum of this disease. Two patients presented with mononeuropathies that are frequently observed in HNPP; the remaining two presented with bilateral neuropathy or mononeuropathy anatomically present in the deep layer. This reflects the broad clinical presentation of HNPP, and clinicians should differentiate these conditions in young patients with monoparesis or bilateral paresis. Although HNPP is currently untreatable, early diagnosis in the emergency department can lead to early detection, eventually resulting in less provocation and recurrence which may cause early motor nerve degeneration.

Keywords: Hereditary sensory and motor neuropathy; Paresis; Peripheral myelin protein 22; Rare disease; Young adult

\section{Introduction}

Hereditary neuropathy with liability to pressure palsy (HNPP) is an autosomal dominant genetic disease that is clinically characterized by recurrent monoparesis and sensory loss, frequently caused by focal compression or trauma [1]. The diagnosis is confirmed by genetic testing and approximately $80 \%$ of patients show deletion of chromosome $17 \mathrm{p} 11.2$ of the peripheral myelin protein 22 (PMP22) gene and the remaining $20 \%$ have a pathogenic variant in PMP22 [2].

The prevalence of HNPP is known to range from 0.84 to 16 per 100,000 people, with ethnic differences [3]. Interestingly, a recent Korean study showed a significantly higher prevalence of 58.9 per 100,000 people, compared to other studies. While this higher prevalence in the Korean population needs further research, it was explained to an extent by the methodology used; the Korean study was a neonatal screening study, while other studies were performed on symptomatic patients. However, we cannot dismiss the possibility of higher frequency of HNPP in the Korean population and its under-recognition. Here, we summarize the clinical features of young male patients with HNPP who came to our emergency department, with this study aiming to improve the identification of HNPP for early and efficient diagnosis.

\section{Cases}

This study was approved by the Institutional Review Board (IRB) of the Kyungpook National University Chilgok Hospital (IRB

Copyright (C) 2020 Yeungnam University College of Medicine

This is an Open Access article distributed under the terms of the Creative Commons Attribution Non-Commercial License (http://creativecommons.org/licenses/by-nc/4.0/) which permits unrestricted non-commercial use, distribution, and reproduction in any medium, provided the original work is properly cited. 
No: KNUCH 2019-06-018). Informed and written consent was obtained from the patients for the case series.

\section{Case 1}

A 34-year-old male presented to our emergency department with left-hand weakness since the morning of the consult. The patient also complained of paresthesia in his left hand. The initial neurological examination showed profound weakness of Medical Research Council (MRC) grade 3 in his left 4th and 5th fingers, along with paresthesia. The results of brain computed tomography (CT) and magnetic resonance imaging (MRI) were normal; and after consultation with the Department of Neurology, nerve conduction and electromyography studies were performed. The electrophysiological study showed multifocal peripheral neuropathy with demyelinating features in all tested nerves, along with conduction block in the left ulnar nerve. The patient's uncle also had a history of symptoms of paralysis. The patient also had a history of recurrent monoparesis and recovery. Genetic testing of the PMP22 gene confirmed gene deletion. At the last follow-up 3 months after the initial presentation, there was nearly full improvement of the symptomatic ulnar neuropathy at the elbow.

\section{Case 2}

A 27-year-old male presented to our emergency department with wrist drop in his right hand after his girlfriend slept on his arm the night before. The initial neurological examination showed weakness in wrist dorsiflexion with an MRC grade 2 and paresthesia in the wrist. The results of brain CT and MRI were normal. An electrophysiological study conducted in the Department of Neurology showed multifocal peripheral neuropathy with demyelination in all tested nerves. The conduction block was observed in the symptomatic right radial nerve. A further probe into the patient's family history revealed that his uncle had experienced similar symptoms a few years ago but recovered without significant sequelae. Subsequent genetic analysis revealed deletion of PMP22. At the last follow-up 3 months after the initial presentation, the patient recovered without any weakness, and a genetic diagnosis of HNPP was made.

\section{Case 3}

A 22-year-old man visited our emergency department with bilateral foot drop. The symptom occurred after crouching for 6 hours while wearing long boots. He also complained of paresthesia in both soles. Brain CT result was normal, and he was immediately referred to the Department of Neurology for consultation. The initial neurological examination showed bilateral weakness in ankle dorsiflexion (MRC grade 3) and bilateral paresthesia in the superficial peroneal nerve territories. This patient denied any family history of similar symptoms. The nerve conduction study showed multifocal demyelinating features in all tested nerves with significant conduction block in both peroneal nerves. Upon confirmation of PMP22 gene deletion, the patient was eventually diagnosed with HNPP. After 4 months, complete recovery was observed.

\section{Case 4}

A 23-year-old male presented with weakness in the left arm after deep sleep. The initial neurological examination showed proximal left arm weakness with an MRC grade 3. Interestingly, the patient had history of wrist drop on the right side after a strenuous drill during his military service. He also recalled that his wrist drop improved after 6 months. He denied any family history of similar symptoms. Result of brain CT and MRI were normal, and after consultation with the Department of Neurology, a nerve conduction study and electromyography were performed. These studies revealed multifocal peripheral neuropathy with demyelination, superimposed by suprascapular neuropathy in the left side. The nerve conduction study showed significantly reduced compound muscle action potential in left suprascapular nerve with active denervations observed in the left supraspinatus and infraspinatus muscles only. Upon confirmation of PMP22 gene deletion, the patient was eventually diagnosed with HNPP. At the end of 3 months, the weakness showed significant improvement.

\section{Discussion}

HNPP is an autosomal dominant hereditary neuropathy caused by deletion of the PMP22 gene. The PMP22 protein is commonly found in the peripheral nerves and plays an important role in myelin compaction; its underexpression is known to cause HNPP [4]. Mild nerve injuries in a common entrapment site are known to cause demyelination and remyelination, leading to altered axonal properties and axonal degeneration in the distal segments. This phenomenon can partly explain the cause of focal entrapment neuropathies in the distal regions as the presenting symptom of HNPP. Notably, PMP22 deletion causes HNPP, while PMP22 duplication causes Charcot-Marie-Tooth disease type 1A. Simultaneous genetic testing via multiplex ligation-dependent probe amplification is possible and is covered by the national insurance system in Korea.

Clinically, a typical case of HNPP presents with a mononeuropathy and is known to involve superficial nerves instead of deep innervated nerves. A previous study showed recurrent involvement of the peroneal nerve around the fibular head, ulnar nerve at 
the elbow, and radial nerves with a frequency of $35 \%, 20 \%$, and $8 \%$, respectively [5]. Along with other nerves (peroneal neuropathy at the fibular head and ulnar neuropathy at wrist level), the median nerve at the wrist is one of the most common compression sites among the patients with HNPP. But an isolated idiopathic carpal tunnel syndrome is rare [2]. Typically, the first symptom occurs as a mononeuropathy in the second or third decade of life, which is consistent with our patients' ages.

The diagnosis of HNPP can be made via electrophysiological study, along with confirmation of PMP22 deletion via genetic analysis. Studies have shown characteristic findings in the nerve conduction study suggestive of HNPP. The general electrophysiological findings of HNPP show features of polyneuropathy with demyelinating features superimposed by focal entrapment neuropathies with slow sensory conduction velocities [6-8]. A recent study that involved HNPP patients under the age of 30 years showed demyelinating features in symptomatic and asymptomatic nerves, with the highest involvement in the ulnar, peroneal, and median nerves. Moreover, there was a significant prolongation of distal motor latency in the tested nerves with slow motor velocities [9]. Another study found a significantly accentuated distal slowing in the median and peroneal nerves with less involvement of ulnar and tibial nerves [10]. These findings are consistent with our case reports, especially in those with a typical HNPP presentation.

Our case series demonstrates both typical and rare types of HNPP showing heterogeneity of clinical presentation to the emergency department (Table 1). The mean age at presentation was 26.5 years, and all patients were male. The typical cases (cases 1 and 2) presented with mononeuropathy in the common entrapment sites in the distal nerves. Therefore, the HNPP diagnosis was quick. However, cases 3 and 4 were rare HNPP cases. There have been reports on extremely rare cases, where the patient has presented with recurrent Bell's palsy [11] and more commonly with proximal limb weakness [10]. A recent study retrospectively reviewed $51 \mathrm{HNPP}$ patients under the age of 30 years and found peroneal and ulnar neuropathy in $30 \%$ of the patients and de- scribed one case of long thoracic and femoral neuropathy that is usually unaffected by compression [8]. Interestingly, in South Korea, where young males are obligated to serve the military, a different pattern of frequency was observed. A 4-year retrospective study of the medical records in the Korean army hospital showed that the most common initial presentation of HNPP was a brachial plexus lesion that showed proximal arm weakness and paresthesia [12]. The authors found brachial plexus lesions in more than $50 \%$ of HNPP patients, which is not in accordance with previous studies in other countries. Moreover, the Korean study stated that the cause of the brachial plexopathy was strenuous push-ups and exercise. This is very similar to case 3 in our study, wherein the patient first experienced symptoms during military service. In case 4, the patient had a very uncommon suprascapular neuropathy which is not usually observed in HNPP. Recent studies have reported a few cases of suprascapular neuropathy in its notch at the supraspinatus fossa caused by strenuous physical activities; this correlates with our patient who also experienced arm weakness after strenuous exercise during his military service [13].

Another report showed an interesting case of bilateral foot drop in an 83-year-old Japanese patient, who experienced symptoms after sitting with their lower legs crossed under their thighs; this presentation was indicative of bilateral common peroneal neuropathy [14]. The patient in case 3, also showed a similar history of prolonged crouching while wearing long boots that caused bilateral common peroneal neuropathy. This is an important finding because HNPP is known to present with mononeuropathy, but the Japanese case and case 3 of our study presented with symmetric bilateral compressive neuropathy.

These rare findings reflect the broad clinical spectrum of HNPP and the different environmental factors among countries that result in a variety of initial presentations in HNPP. More studies are needed to understand the Korean phenotypes in HNPP, as well as HNPP in patients over 30 years old; our case series demonstrates the need for more documented cases from different countries.

The limitation of this retrospective case series is the number of patients enrolled. This was inevitable because we only enrolled

Table 1. Clinical features of HNPP patients

\begin{tabular}{|c|c|c|c|c|c|}
\hline Patient & Sex/age (yr) & Position & Clinical presentation & Trigger & $\begin{array}{l}\text { Family } \\
\text { history }\end{array}$ \\
\hline 1 & & & $\begin{array}{l}\text { Weakness in the left } 4 \text { th and } 5 \text { th fingers (MRC grade } 3 \text { ) } \\
\text { along with paresthesia }\end{array}$ & & \\
\hline 2 & Male/27 & Radial nerve & Wrist drop in the right hand after it was slept on & Sleep-related compression & Yes \\
\hline 3 & Male/22 & Bilateral peroneal nerve & Bilateral foot drop and paresthesia in both soles & After prolonged crouching & No \\
\hline 4 & Male/23 & Suprascapular nerve & Proximal left arm weakness with MRC grade 3 & After carrying a heavy backpack & No \\
\hline
\end{tabular}

HNPP, hereditary neuropathy with liability to pressure palsy; MRC, Medical Research Council. 
HNPP patients who primarily visited our emergency department and not our out-patient clinic. Although HNPP is still an untreatable genetic disease, environmental factors that can aggravate monoparesis and eventually lead to further deterioration should be avoided. As there is no specific clue that can lead to the diagnosis of HNPP, it is important for neurologists and emergency department doctors to be aware of these conditions to make a differential diagnosis leading to an early diagnosis and prevent further deterioration of the vulnerable peripheral nerves in patients with HNPP.

\section{Acknowledgments}

\section{Conflicts of interest}

No potential conflict of interest relevant to this article was reported.

\section{Author contributions}

Conceptualization, Formal analysis, Investigation, and Supervision: JSP; Data curation: CK; Writing-original draft: CK; Writing-review \& editing: JSP.

\section{ORCID}

Changho Kim, https://orcid.org/0000-0002-7552-8200

Jin-Sung Park, https:/ /orcid.org/0000-0001-5506-9206

\section{References}

1. Dubourg O, Mouton P, Brice A, LeGuern E, Bouche P. Guidelines for diagnosis of hereditary neuropathy with liability to pressure palsies. Neuromuscul Disord 2000;10:206-8.

2. Bird TD. Hereditary neuropathy with liability to pressure palsies. 1998 Sep 28 [updated 2014 Sep 25]. In: Adam MP, Ardinger HH, Pagon RA, Wallace SE, Bean LJ, Stephens K, et al., editors. GeneReviews ${ }^{\circledast}$ [Internet]. Seattle (WA): University of Washington, Seattle; 1993-2020 [cited 2020 Jun 5]. https:// www.ncbi.nlm.nih.gov/books/NBK1392/.

3. Park JE, Noh SJ, Oh M, Cho DY, Kim SY, Ki CS. Frequency of hereditary neuropathy with liability to pressure palsies (HNPP) due to $17 \mathrm{p} 11.2$ deletion in a Korean newborn population. Orphanet J Rare Dis 2018;13:40.
4. Schenone A, Nobbio L, Caponnetto C, Abbruzzese M, Mandich P, Bellone E, et al. Correlation between PMP-22 messenger RNA expression and phenotype in hereditary neuropathy with liability to pressure palsies. Ann Neurol 1997;42:86672.

5. Celik Y, Kilincer C, Hamamcioglu MK, Balci K, Birgili B, Cobanoglu S, et al. Hereditary neuropathy with liability to pressure palsies in a Turkish patient (HNPP): a rare cause of entrapment neuropathies in young adults. Turk Neurosurg 2008; 18:82-4.

6. Ichikawa K, Nezu A. Hereditary neuropathy with liability to pressure palsies in childhood: report of a case and a brief review. Brain Dev 2005;27:152-4.

7. Andersson PB, Yuen E, Parko K, So YT. Electrodiagnostic features of hereditary neuropathy with liability to pressure palsies. Neurology 2000;54:40-4.

8. Hong YH, Kim M, Kim HJ, Sung JJ, Kim SH, Lee KW. Clinical and electrophysiologic features of HNPP patients with 17p11.2 deletion. Acta Neurol Scand 2003; 108:352-8.

9. Robert-Varvat F, Jousserand G, Bouhour F, Vial C, Cintas P, Echaniz-Laguna A, et al. Hereditary neuropathy with liability to pressure palsy in patients under 30 years old: neurophysiological data and proposed electrodiagnostic criteria. Muscle Nerve 2018;57:217-21.

10. Li J, Krajewski K, Shy ME, Lewis RA. Hereditary neuropathy with liability to pressure palsy: the electrophysiology fits the name. Neurology 2002;58:1769-73.

11. Drouet A, Guilloton L, Latour P, Ribot C. Recurrent facial nerve paralysis in hereditary neuropathy with liability to pressure palsy. Presse Med 2000;29:655.

12. Kim KE, Yeom J. Proximal arm weakness is the most common presentation in young Korean soldiers diagnosed as having hereditary neuropathy with liability to pressure palsy (HNPP). J R Army Med Corps 2016;162:352-4.

13. Lorenzoni PJ, Kay CS, Cavalet C, Arndt RC, Werneck LC, Scola RH. Hereditary neuropathy with liability to pressure palsies: a single-center experience in Southern Brazil. Neurol Int 2016;8:6677.

14. Kawaguchi N, Suzuki N, Tateyama M, Takai Y, Misu T, Nakashima I, et al. Two cases of elderly-onset hereditary neuropathy with liability to pressure palsy manifesting bilateral peroneal nerve palsies. Case Rep Neurol 2012;4:149-55. 